\title{
We ask: What is the diagnosis?
}

\section{DANY JASINOWODOLINSK1' ${ }^{1}$, GILBERTO SZARF², NESTOR L MÜLLER ${ }^{3}$}

A 66-year-old patient with a history of chronic lymphedema of the lower extremities, accompanied by recurrent pneumonia and pleural effusion.

Presenting chronic cough with sputum that is colorless but abundant in the mornings.
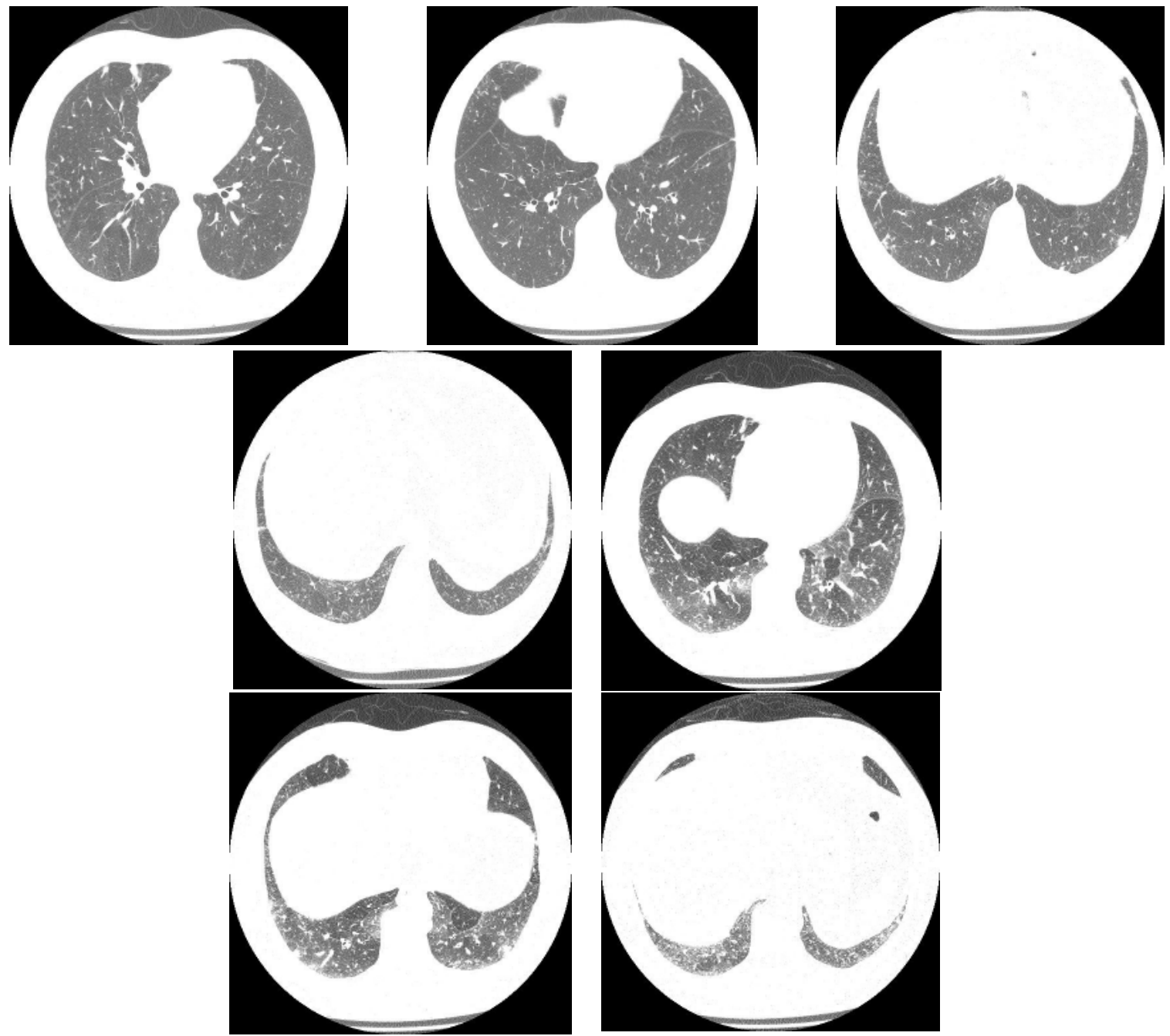

This section is intended to encourage a diagnostic approach based on clinical and radiographic findings. We invite all of our readers to participate.

Submit your diagnosis by completing the form you will find on our website (www.jornaldepneumologia.com.br) or by sending an e-mail to jpneumo@terra.com.br. Remember to include the full name of your institution. The images shown here are those that were most relevant in making the final diagnosis. The diagnosis for this case, along with the names of readers who submitted correct responses, will be published in the next issue of the journal.

1. Attending Radiologist at the Fleury Center for Diagnostic Medicine, São Paulo, São Paulo, Brazil

2. Doctoral student in Radiology at the Universidade Federal de São Paulo (UNIFESP, Federal University of São Paulo), São Paulo, São Paulo, Brazil

3. Full Professor of Radiology at the University of British Columbia, Vancouver, British Columbia, Canada 